\title{
A RELAÇÃo ENTRE FILOSOFIA POLÍTICA E DEMOCRACIA NA OBRA DE MICHAEL WALZER
}

\author{
Ricardo Corrêa de Araujo ${ }^{1}$ \\ Universidade Federal do Espírito Santo (UFES) \\ iD https://orcid.org/0000-0002-0431-8599
}

\begin{abstract}
RESUMO:
O objetivo deste artigo é apresentar a relação entre Filosofia política e democracia na obra de Michael Walzer, a partir da influência exercida sobre ele por John Rawls. Para fazer isto, será feita uma breve apresentação das visões de Rawls sobre aquela relação. Após, será mostrado que Walzer corrobora e amplia a concepção de Rawls. Por último, será descrito o papel de crítica imanente que Walzer atribui à Filosofia política nas democracias contemporâneas, trazendo-a da pretensão de guia da política, baseada na contemplação privilegiada de qualquer suposta ordem transcendente e vinculante, para um papel de engajamento comprometido apenas com a própria ordem democrática.
\end{abstract}

PALAVRAS-CHAVE: Filosofia política; Democracia; Michael Walzer.

\section{THE RELATIONSHIP BETWEEN POLITICAL PHILOSOPHY AND DEMOCRACY AT MICHAEL WALZER'S WORK}

\begin{abstract}
:
The aim of this paper is to present the relationship between political philosophy and democracy in the Michael Walzer's work, influenced by John Rawls. To do this, it will be done a brief presentation of Rawls's views about that relationship. After, it will be shown that Walzer corroborates and expands the Rawls's conception. Finally, it will be described the role of immanent critique that Walzer attributes to political philosophy in contemporary democracies, turning it rather policy's guide, based on privileged contemplation of any alleged transcendent and binding order, into a committed engagement only with the very democratic order.
\end{abstract}

\footnotetext{
${ }^{1}$ Doutor em Filosofia e professor da Universidade Federal do Espírito Santo (UFES), Espírito Santo - Brasil. E-mail: rcaerca@uol.com.br
} 
KEYWORDS: Political philosophy; Democracy; Michael Walzer.

\section{Introdução}

A Filosofia política contemporânea é fortemente marcada pela obra de John Rawls. Até mesmo seus críticos reconhecem que ela é o principal marco teórico a partir do qual se inserem as discussões filosóficas sobre política das últimas décadas: "É geralmente aceito que o recente renascimento da filosofia política normativa começou com a publicação de A Theory of Justice, de John Rawls, em 1971[...]". (KYMLICKA, 2006, p. 11) Alguns dos mais reconhecidos filósofos políticos recentes, como Michael Sandel, Alasdair MacIntyre, Charles Taylor, Will Kymlicka, Robert Nozick, Jürgen Habermas, Ronald Dworkin, Richard Rorty e Michael Walzer, entre outros, se inseriram nos debates gerados a partir da recepção daquela obra rawlsiana. Esta afirmativa é confirmada pelo próprio Walzer, ao falar sobre a origem de Esferas da justiça, um dos seus livros mais importantes: "Rawls's book came out in 71, but chapters of it had been circulating in Cambridge in mimeograph form for years before that. So, yes, I was responding to that book[...]." (WILLIAMS, 2012, p. 382) Dentre aqueles debates diretamente provocados por Rawls, costuma-se destacar os que envolveram utilitaristas e liberais, liberais igualitaristas e libertaristas e, por fim, comunitaristas e liberais. ${ }^{2}$ Todavia, mesmo se não chegou a ser amplamente reconhecida como outro destes debates filosóficos, a relação entre a Filosofia e a democracia se tornou um problema constante nas últimas décadas. Isto ocorreu especialmente pela recepção dada à famosa injunção de Rawls, no sentido de que a sua Filosofia política, a justiça como equidade, não deveria se envolver em controvérsias filosóficas, tais como a natureza do eu ou a existência de uma ordem moral transcendente, justamente porque aquelas não poderiam ser resolvidas politicamente: "Assim, a justiça como eqüidade permanece na superfície, filosoficamente falando." (RAWLS, 1992, p. 33)

As interpretações desta exigência de "superficialidade filosófica" variaram amplamente, desde tentativas de minimizar a sua força, tomando-a como um mero excesso retórico, até radicalizações que levaram à negação de qualquer utilidade da Filosofia política. ${ }^{3}$ Um bom exemplo destes dois extremos pode ser visto na crítica que Richard Bernstein faz à interpretação de Richard Rorty:

What is even more surprising is that Rorty never even mentions what - on any interpretation of Rawls - is the heart of his

${ }^{2}$ Cf. SANDEL, p. 243-244.

3 "A Filosofia é uma escada pela qual subiu o pensamento político do Ocidente e depois deixou de lado.” (RORTY, 2013, p. 86) 
theory, that is, the successive formulations and defense of the two principles of justice. [...] Rorty is concerned (one is tempted to say 'obsessed') with variations on a single theme the meta-theoretical question of whether Rawls's enterprise is one of 'articulation' of common intuitions and shared beliefs or 'justification' of liberal democracy. (BERNSTEIN, 1987, p. 545)

A "questão metateórica" polêmica é se o empreendimento de Rawls pretende apenas articular, de modo filosoficamente superficial, as crenças compartilhadas pelas democracias ou se pretende justificar, fundamentandoa filosoficamente, a existência das próprias democracias. Este é justamente o ponto central do debate sobre o significado da superficialidade filosófica, com Bernstein defendendo seu caráter periférico em relação aos princípios de justiça, suposto "coração da teoria" rawlsiana, e com Rorty tomando aquela como a principal, talvez única, questão a ser discutida. $\mathrm{O}$ caso é que estes dois polos perdem algo importante sobre a exigência de superficialidade de Rawls quando, respectivamente, a ignoram ou se fixam nela. De fato, ao ignorá-la, a Filosofia política acaba sendo objeto de acusações pertinentes de um insustentável, obsoleto e autoritário fundacionismo metafísico, ignorante do "fato do pluralismo" e incompatível com a tolerância democrática. ${ }^{4}$ Por outro lado, a "obsessão" com aquela questão metateórica pode causar um desinteresse por questões filosóficas que têm implicações políticas decisivas, tais como as possíveis e controversas maneiras concretas de realizar os ideais democráticos da igualdade e da liberdade. ${ }^{5}$

Este artigo não cobre todo este espectro interpretativo, analisando em profundidade as consequências das suas posturas extremas, mas trata o modo como Michael Walzer, que levou a sério aquela exigência antifundacionista de Rawls sem nela se fixar, pensa a relação entre Filosofia política e democracia. Para fazer isto, inicialmente, será feita uma breve exposição das razões dadas por Rawls para que a Filosofia política deva recusar a tradicional tarefa de tentar justificar ou fundamentar filosoficamente a democracia. Após, será mostrado o modo como Walzer corrobora e amplia aquelas razões, inclusive refutando a acusação de relativismo a elas imputada. Por último, será descrito o papel de crítica imanente que Walzer atribui à Filosofia política nas democracias

\footnotetext{
4 "uma sociedade democrática moderna não se caracteriza apenas por um pluralismo de doutrinas religiosas, filosóficas e morais abrangentes, e sim por um pluralismo de doutrinas incompatíveis entre si e que, no entanto, são razoáveis. Nenhuma dessas doutrinas é professada pelos cidadãos em geral.” (RAWLS, 2011, p. XVII).

5 "What I find most objectionable in Rorty's strategy is that it divert us from the pragmatically important issues that need to be confronted.[...] 'Liberalism' itself is a vague term that embraces many diverse and even incompatible positions." (BERNSTEIN, 1987, p. 546)
} 
contemporâneas, trazendo-a da pretensão de guia da política, baseada na contemplação privilegiada de qualquer suposta ordem transcendente e vinculante, para um papel de engajamento comprometido apenas com a própria ordem democrática. Assim, será mostrado que Walzer, como recomendado por Rawls, "permanece na superfície" e, simultaneamente, propõe um papel não apenas teórico, mas também político e democrático, para a Filosofia política contemporânea.

\section{0 fundacionismo da Filosofia política tradicional e a exigência rawlsiana de superficialidade filosófica.}

A Filosofia política tradicional, desde Platão e com poucas exceções, buscou fundamentar a ação política em uma ordem antecedente às próprias comunidades que deveriam ser reguladas por tal ordem, a ser apreendida por uma doutrina abrangente: "The more familiar view of political philosophy is that its concepts, principles and ideals, and other elements are presented as consequences of comprehensive doctrines, religious, metaphysical, and moral." (RAWLS, 1995, p. 133) Por isto, as noções do bom e do justo, por exemplo, nunca foram tomadas como resultado contingente da dinâmica sócio-política de cada comunidade, mas como representações de algo exterior, atemporal e inumano. Então, caberia aos filósofos encontrar os meios de prospecção capazes de desobstruir o caminho das aparências até chegar a representar adequadamente, isto é, de forma verdadeira, aquela realidade última, sistematizando seu significado e extraindo suas consequências políticas. Todavia, a partir da recepção da obra de Nietzsche no século XX, amplificada por filósofos de várias procedências, e dos desenvolvimentos autônomos de várias disciplinas e correntes filosóficas contemporâneas, da Epistemologia à Ética, ocorreu que as concepções fundacionistas, como aquela da Filosofia política tradicional, se tornaram cada vez mais insustentáveis, configurando uma espécie de consenso filosófico em torno da rejeição ao fundacionismo: "Los que participan em el debate filosófico coinciden hoy, al menos, en un punto: no admiten una fundamentación única, última, normativa." (VATTIMO, Gianni, 1988, p. $11)^{6}$

No específico âmbito da Filosofia política, vários filósofos têm instado as comunidades democráticas a se livrarem da ideia de encontrar um fundamento a-histórico para as suas próprias crenças, instituições e práticas históricas. Isto ocorreu especialmente a partir da virada teórica que Rawls realizou, quando passou a incluir, entre as condições da sua justiça como

\footnotetext{
${ }^{6}$ Até mesmo um filósofo como Habermas, quase sempre associado ao que se costuma considerar a "linhagem kantiana" da Filosofia e, portanto, ainda disposto a sustentar a incondicionalidade e a universalidade da verdade, faz questão de se separar do fundacionismo em sentido forte, dispondo-se a "[...] abandonar o esforço inauspicioso de uma fundamentação dedutiva de 'últimos' princípios[...].” (HABERMAS, 2003, p. 103)
} 
equidade, a exigência de "superficialidade filosófica", tendência não fundacionista que estava ausente em "Uma teoria da justiça", mas que se tornou dominante em meados da década de oitenta do século passado. De fato, motivado pelo reconhecimento do fato do pluralismo nas democracias, isto é, pela coexistência de concepções do bem inevitavelmente diversas, incomensuráveis e, eventualmente, conflitantes, Rawls abandonou a ideia de tentar justificar filosoficamente as democracias, voltando as costas àquela ideia tradicional de fundamentação da ação política na suposta realidade última. A partir daí, ele passou a considerar a "justiça como equidade" não mais como uma doutrina filosófica abrangente da justiça, que seria aplicável a todos os aspectos da vida humana, mas como uma concepção política de justiça, isto é, aplicável apenas à estrutura básica de sociedades democráticas, composta por suas instituições políticas, sociais e econômicas: "Ao se transformar a doutrina abrangente da justiça como equidade na concepção política da justiça como equidade[...].”(RAWLS, 2011, p. XLVIII) Assim, ele aceitou que não seria possível construir justificativas não circulares para as instituições e práticas políticas de qualquer comunidade, voltando-se para a possibilidade mais profícua de articular filosoficamente as crenças compartilhadas pelos cidadãos das comunidades democráticas, solo cultural e histórico comum que ele chamou de "consenso sobreposto" (overlaping consensus). ${ }^{7}$

Isto significa que o ponto de partida da justiça como equidade passou a ser aquele conjunto de crenças, práticas e instituições historicamente partilhadas pelos membros das comunidades democráticas, enquanto os princípios de justiça, a ser filosoficamente articulados, são posteriores àquilo que se partilha no consenso sobreposto. Obviamente, aqui, tais princípios não podem mais ser tomados como fundamento, já que são obtidos a posteriori. Assim, a Filosofia política rawlsiana, o seu liberalismo político, pode deixar de lado todas as doutrinas abrangentes, inclusive as filosóficas, movendo-se apenas no âmbito político:

The central idea is that political liberalism moves within the category of the political and leaves philosophy as it is. It leaves untouched all kinds of doctrines, religious, metaphysical, and moral, with their long traditions of development and interpretation. (RAWLS, 1995, p. 134)

\footnotetext{
7 “Consideramos, então, nossa própria cultura política pública, incluindo nela suas principais instituições e as tradições históricas de sua interpretação, como o fundo compartilhado de ideias e princípios básicos implicitamente reconhecidos.”(RAWLS, 1992, p. 31)
} 
Como já visto, a atitude de "deixar intocadas" as doutrinas abrangentes, inclusive os liberalismos abrangentes de Kant e de Stuart Mill, ${ }^{8}$ na construção teórica do liberalismo político rawlsiano não é uma opção, mas uma necessidade derivada diretamente do reconhecimento do fato do pluralismo, pois o "[...]liberalismo como doutrina política presume que num Estado constitucional nas condições modernas a tendência é haver concepções conflitantes e incomensuráveis do bem." (RAWLS, 1992, p. 51) Isto significa, por exemplo, que alguns cidadãos de uma sociedade democrática podem sustentar que os indivíduos são sempre absoluta e necessariamente autônomos, em um sentido metafisico forte, enquanto outros podem crer que a autonomia individual deve ser submetida à lei divina, ou a algo do gênero. Seja como for, Rawls qualifica as doutrinas abrangentes, que sustentam uma ou outra destas hipóteses, como fundacionistas e, portanto, as considera inutilizáveis, em tal condição pluralista, para justificar e regular a liberdade política dos cidadãos de uma democracia. Pelo contrário, ao permanecer na superfície, isto é, ao negar o fundacionismo, e tentar articular princípios de justiça derivados apenas de nossas próprias crenças, práticas e instituições, sem apelar para doutrinas abrangentes, o "liberalismo como doutrina política" se mostra persuasivamente como uma melhor alternativa para as democracias pluralistas.

Certamente, o conteúdo desta alternativa proposta por Rawls, especialmente quanto aos princípios de justiça, não foi sequer indicado aqui. Além disso, a oposição entre a exigência de superficialidade e o fundacionismo, isto é, a questão metateórica, é apenas o ponto de partida para obter tais princípios, "coração da teoria" rawlsiana. Porém, a obtenção filosófica destes ou de outros princípios de justiça, em sociedades democráticas pluralistas, não seria possível sem o tratamento adequado daquela questão, que coloca em cena a relação entre Filosofia e democracia, que é aquilo que interessa neste artigo. Portanto, veremos agora como é que Walzer trará novos elementos para rejeitar o fundacionismo na Filosofia política, mostrando-o como constitutivamente incompatível com as democracias pluralistas, ao mesmo tempo em que se esquiva das acusações de relativismo.

\section{Fundacionismo, relativismo e a possível tensão entre Filosofia e democracia.}

Já foi visto que Walzer assume que tentou responder ao livro "Uma teoria da justiça", de Rawls, com o seu próprio livro "Esferas da justiça". É certo que as propostas deste último e os resultados obtidos por ele podem ser vistos como reações (Cf. WILLIAMS, 2012, p. 382), todavia, a

\footnotetext{
8 "In political liberalism, autonomy is understood as political and not as moral autonomy[...].The latter is a much wider idea and belongs to comprehensive doctrines of the kind associated with Kant and Mill." (RAWLS, 1995, p. 154)
} 
influência de Rawls sobre Walzer não é apenas "negativa" e externa, provocando aquela tentativa de resposta, mas também formativa:

My philosophical education, since I hadn't had one as a graduate student or an undergraduate, was in a discussion group called SELF, the Society for Ethical and Legal Philosophy, that included Rawls and Dworkin and Nagel and Nozick[...] and a few other people. (WILLIAMS, 2012, p. 381)

Esta "educação filosófica" tornou Walzer familiarizado com um novo modo de se escrever Filosofia política e com seus temas específicos, já que alguns dos seus antigos colegas da SELF foram diretamente responsáveis por tal tendência. Esta se tornaria dominante nas décadas seguintes, inicialmente nos países anglófonos e posteriormente em boa parte do mundo filosófico. ${ }^{9} \mathrm{O}$ caso é que Walzer acabou se ligando a estes novos temas, tais como justiça, democracia e comunidade, sendo habitualmente considerado um comunitarista e assumindo-se como tal, ${ }^{10}$ isto é, como alguém que avalia os ideais de justiça e os principais ideais democráticos, igualdade e liberdade, sempre sob o ponto de vista da comunidade política envolvida. ${ }^{11}$

Por outro lado, ele jamais assimilou o projeto comum aos membros da SELF, tal como descrito por um deles: "Such philosophers try to find some inclusive formula that can be used to measure social justice in any society[...]."(DWORKIN, 1983, p. ?) ${ }^{12}$ O fato é que esta pretensão de que as fórmulas ou princípios de justiça formulados pelos filósofos possam valer para qualquer sociedade entra em conflito com a visão comunitarista de Walzer, voltada justamente para refletir sobre comunidades particulares e a partir delas mesmas. ${ }^{13}$ É através deste conflito de visões que Walzer explica as duras críticas contra seu livro "Esferas da justiça" feitas por Ronald Dworkin, seu antigo colega do SELF: [...]he thought that my book was a

\footnotetext{
9 “[...]a análise conceitual do significado do poder, da soberania ou da natureza da lei. Estes eram tópicos populares há vinte e cinco anos, mas a ênfase recente tem caído sobre os ideais de justiça, liberdade e comunidade, que são invocados na avaliação de instituições e procedimentos políticos." (KYMLICKA, 2006, p. 1)

10 "The communitarian critique is nonetheless a powerful one[...]. In this essay, I want to investigate the power of its current American versions and then offer a version of my own[...]. (WALZER, 1990, p. 7)

11 "What I am proposing here is that we think about local distributive justice in much the same way as we think about self-determination and the politics of liberation. Each collective self must determine itself by itself." (WALZER, 2011, p. 47)

${ }^{12}$ Como já vimos, após sua virada em direção ao liberalismo político, Rawls se afasta desta pretensão de usar sua própria "fórmula", a justiça como equidade e seus princípios de justiça, em "qualquer" sociedade, limitando-se àquelas que chamou de sociedades democráticas (Cf. RAWLS, 1992, p. 27).

13 "Determinada sociedade é justa se sua vida substantiva é vivida de determinada maneira - isto é, de maneira fiel às interpretações em comum dos membros." (WALZER, 2003, p. 430)
} 
kind of betrayal of the philosophical enterprise, whose goal is to find the True and the Good, which must be singular in character. I was never at home with that view or sympathetic to it. (WILLIAMS, 2012, p. 382)

A questão é que Dworkin não realizou a mesma virada política que Rawls, permanecendo vinculado a uma concepção fundacionista e universalista da Filosofia. Assim, esta deveria buscar não o que a justiça significa em determinada comunidade, mas sim algo que transcende toda comunidade particular e que, portanto, deveria ser o objetivo do filósofo. Esta posição de Dworkin, comum a toda Filosofia política tradicional, é descrita por Walzer de modo emblemático: The stance of the philosopher is very different. The truths he commonly seeks are universal and eternal, and it is unlikely that they can be found from the inside of any real and historic community. (WALZER, 1981, p. 388)

Portanto, do ponto de vista fundacionista e universalista de Dworkin, a busca de Walzer por concepções de justiça locais, aplicáveis às respectivas comunidades reais e históricas em que aquelas podem ser articuladas (Cf. WALZER, 2003, p. 430, já citado na nota 13), deve necessariamente parecer uma "espécie de traição do empreendimento filosófico" e, inclusive, a mais grave delas, a traição do relativismo: "Walzer's relativism is faithless to the single most important social practice we have: the practice of worrying about what justice really is." (DWORKIN, 1983, p. ?) Porém, Dworkin não leva em conta as consequências da sua própria afirmativa de que este tipo de pergunta pela essência da justiça, "universal e eterna", aquilo que "a justiça realmente é", é uma prática social que "nós temos". Ele não considera que se trata de uma prática que ocorre no interior das comunidades democráticas, marcadas historicamente pela Filosofia fundacionista e que, portanto, creem na existência de algo transcendente, no caso, a justiça, cuja essência poderia ser apreendida por uma doutrina filosófica abrangente. Na perspectiva de Walzer, é apenas por falar a partir de uma comunidade com este tipo de crença que Dworkin pode considerar a possibilidade de obter filosoficamente o que "a justiça realmente é" para qualquer comunidade, inclusive para as que não partilham tal crença.

Contrariamente, a visão comunitarista e não fundacionista de Walzer, embora também procure por princípios de justiça, assume que estes poderão ser úteis, de início, apenas para a comunidade a que ele mesmo pertence:

I don't hope to make arguments that are conclusive for all human beings in all societies that exist or will exist or have ever existed. I don't subscribe to the idea - it seems to me distinctly odd - that the principles of justice appropriate to Americans must be appropriate as well to ancient Babylonians. (WALZER, 1983, p. ?)

Todavia, mesmo julgando "claramente estranha" esta ideia fundacionista tradicional, de que os mesmos princípios de justiça deveriam 
ser apropriados para qualquer tempo e lugar, Walzer não considera que, para uma mesma comunidade e em um mesmo momento, haja múltiplos e incomensuráveis princípios de justiça, de modo que a justiça seria relativa a tais princípios, adotados por pessoas diferentes e por razões diversas. Pelo contrário, negando o relativismo de que é acusado, ele afirma compartilhar com Dworkin a ideia de que há uma noção de justiça capaz de fundamentar uma decisão justa em casos polêmicos: "I share Dworkin's sense that in a particular case, in a particular culture, there is, in principle, a right decision." (WALZER, 1983, p.?). A diferença é que Walzer limita o âmbito de validade desta noção apenas à comunidade particular e ao momento em que se discute a questão, renunciando à pretensão de validade universal e atemporal. Assim, a crítica social que pretenda mostrar uma decisão ou uma prática social como justa ou injusta, porque se adequaria ou não à noção de justiça, precisa recorrer àquilo que a comunidade envolvida compartilha, isto é, àquele tipo de reservatório comunitário que Rawls chamou de consenso sobreposto:

Social critics commonly don't, and certainly needn't, invent the principles they apply; they don't have to step outside the world they ordinarily inhabit. They appeal to internal principles, already known, comprehensible to, somehow remembered by, the people they hope to convince." (WALZER, 1983, p. ?)

Como visto, Walzer segue Rawls ao negar o valor das doutrinas abrangentes para realizar a crítica social ou para decidir o que é justo em casos polêmicos, sem levar em conta aquilo que é interno às comunidades a cada vez envolvidas e que é partilhado por seus membros. Mas, além disso, Walzer também rejeita o fundacionismo universalista da Filosofia política tradicional pelo que considera seu caráter autoritário: "Philosophical founding is an authoritarian business." (WALZER, 1981, p. 381) A princípio, esta parece uma afirmativa incompatível com a autoimagem da Filosofia como possuidora, talvez até mesmo a criadora, de um discurso argumentativo, reflexivo e crítico. Todavia, as doutrinas filosóficas abrangentes, justamente enquanto tais, são profundamente afetadas pelo próprio caráter daquilo que pretendem apreender e enunciar, isto é, princípios universal e incondicionalmente válidos que não podem ser democraticamente contraditados: "The claim of the philosopher in such a case is that he knows 'the pattern set up in the heavens.' He knows what ought to be done.[...]Here in its simplest form is the tension between philosophy and democracy." (WALZER, 1981, p. 383)

Walzer percebe esta tensão entre Filosofia e democracia derivando da pretensão injustificada de um elemento externo determinar um ambiente interno. Para ele, a noção de justiça que proporciona a obtenção da decisão justa em uma dada comunidade política não pode ser colhida por uma doutrina abrangente, que pretenda trazê-la do exterior, pois modelos 
estrangeiros, sem cidadania, mesmo que "estabelecidos nos céus", não podem pretender determinar as decisões dos cidadãos para regular seu próprio convívio:

This attitude is philosophical restraint, and it is simply the respect that outsiders owe to the decisions that citizens make among themselves and for themselves. The philosopher has withdrawn from the community. It is precisely because the knowledge he seeks can only be found outside this particular place that it yields no rights inside. (WALZER, 1981, p. 396)

Portanto, Walzer recusa o fundacionismo metafísico e adere à superficialidade filosófica rawlsiana, mostrando não apenas a inviabilidade do primeiro, diante do fato do pluralismo, como também seu caráter autoritário e antidemocrático. Além disso, ele refuta a acusação de relativismo irrestrito apelando para a possibilidade de recurso a noções de justiça locais, conectadas às comunidades. Esta possibilidade indica um papel diferente do tradicional para a Filosofia política, o que será desenvolvido a seguir.

\section{A Filosofia política nas comunidades democráticas.}

A partir do viés antifundacionista da Filosofia política inaugurado por Rawls, que é adotado por Walzer, este defende a necessidade de reflexão filosófica sobre o papel que a própria Filosofia deve desempenhar, nas sociedades democráticas, se levar a sério a exigência rawlsiana de superficialidade filosófica. Porém, como já visto, Walzer não se torna "obcecado" pela questão metafilosófica que opõe uma suposta necessidade de fundamentação filosófica da democracia, por um lado, e a possibilidade de mera articulação das crenças subjacentes às práticas democráticas, por outro. De fato, ele se interessa também pelas questões políticas concretas que afetam as sociedades democráticas. Esta aparente oscilação é mediada por Walzer justamente pela sua tentativa de produzir uma Filosofia engajada teórica e politicamente nas vicissitudes das democracias:

I want to talk as a philosopher today - a practical and engaged philosopher. I won't argue for particular policies, but I also won't remain at the level of abstract principles. If philosophy is to engage with politics, it had better be political, not metapolitical, philosophy. (WALZER, 1998, ?)

Isto significa que, se não pretende ficar no nível dos princípios abstratos, isto é, como uma Filosofia metapolítica, nem como mera apologia teórica de políticas particulares, a Filosofia, para ser propriamente política, deve se voltar teórica, prática e premeditadamente, adotando a necessária superficialidade filosófica, para as questões concretas da comunidade 
política a que pertence ou a que se refere. Este é o tipo de Filosofia, engajada ou envolvida politicamente, que Walzer propõe: "But when philosophers write about public affairs, I believe that they must attend [philosophically] to the political and moral realities of the world whose affairs these are." (WALZER, 2007, p. 309) Trata-se obviamente de um ponto controverso, pois há grande divergência sobre a proximidade filosófica adequada para examinar as "realidades políticas e morais". Todavia, antes de examiná-lo, é preciso tratar a questão da visão comunitarista de Walzer, pois é ela que justifica seu foco nas questões específicas das sociedades democráticas e não simplesmente nas questões políticas e morais em geral, como sempre procedeu a Filosofia política tradicional.

A visão de Filosofia política de Walzer passa pela sua distintiva concepção do comunitarismo: "My communitarianism is pluralist, and that in itself distinguishes me from some others communitarians." (WILLIAMS, 2012, p. 386). Tal distinção vem do fato dele, longe de imaginá-lo como uma receita universal, concebê-lo como pluralista, isto é, como algo que deve se concretizar de modo particular em cada comunidade concreta: "Each collective self must determine iself by itself. The process is reiterative." (WALZER, 2011, p. 47) Portanto, a visão comunitarista de Walzer não é uma teoria abstrata e universalista, sem qualquer procedência cultural e histórica, que teria a pretensão paradoxal de universalizar uma recomendação de idêntico comunitarismo para todas as sociedades. Pelo contrário, ela é enraizada em um tipo específico de comunidade, as sociedades democráticas, e voltada para estas: “[...]o comunitarismo deve ser compreendido como um corretivo da teoria e da prática liberais (mais do que como uma doutrina autônoma ou um programa político substantivo)." (WALZER, 2008, p. X) Isto implica que as constantes referências que, seguindo Rawls, ${ }^{14}$ Walzer faz à comunidade, enquanto depositária das crenças e práticas relevantes para guiar seu próprio rumo e como instância última a que se pode recorrer para estabelecer o que é justo, por exemplo, não valem igualmente para qualquer comunidade, pois pode haver aquelas que aspirem legitimamente a "verdades universais": "[...]I do not doubt that particular communities improve themselves by aspiring to realize universal truths and by incorporating (particular) features of philosophical doctrine into their own ways of life." (WALZER, 1981, p. 394)

Todavia, na perspectiva de Walzer, este não pode mais ser o caso das comunidades democráticas, nas quais vigoram "a teoria e a prática liberais", pois aquelas, reconhecendo o fato do pluralismo, não devem mais "incorporar doutrinas filosóficas" fundacionistas e universalistas para

\footnotetext{
14 ، “...]posto que a justiça como equidade se propõe como uma concepção política da justiça para uma sociedade democrática, ela procura valer-se apenas das ideias intuitivas básicas que estão inscritas nas instituições de um regime constitucional democrático e nas tradições públicas da sua interpretação.” (RAWLS, 1992, p. 28)
} 
realizar sua autorregulação: "It is a mistake to attempt any extensive incorporation of philosophical principles into the law either by interpretation or amendment." (WALZER, 1981, p. 393). De fato, tais doutrinas e princípios filosóficos fundacionistas se mostram totalmente incompatíveis com as crenças e práticas atuais das democracias, de modo que estas deveriam aplicar a si mesmas o seu "corretivo" comunitarista, que se volta para a tarefa da articulação filosófica de tais crenças como possibilidade de obtenção de parâmetros locais de justiça. Obviamente, a influência de Rawls se faz sentir fortemente aqui, pois o projeto rawlsiano pode bem ser resumido como uma tentativa de articular as crenças do "consenso sobreposto" (overlaping consensus) das comunidades democráticas, derivando delas uma concepção política de justiça que funcione como um princípio crítico, como algo que elas possam utilizar para julgar se suas instituições e práticas correspondem ou não àquelas crenças compartilhadas que professam:

[...]teremos de descobrir uma nova maneira de organizar ideias e princípios familiares numa concepção de justiça política[...]. Nesse caso, essa concepção oferece um ponto de vista publicamente reconhecido, do qual todos os cidadãos podem examinar, uns perante os outros, se suas instituições políticas e sociais são justas ou não. (RAWLS, 1992, p. 32)

Esta passagem, bastante conhecida, trata de dois momentos distintos. O primeiro, aquele de "organizar ideias e princípios" em uma concepção de justiça política, é facilmente reconhecido como uma tarefa filosófica. $\mathrm{O}$ fato desta concepção ser posterior àquilo que é compartilhado no consenso sobreposto de determinada comunidade - em vez de ser uma concepção a priori, independente de qualquer comunidade contingente e, portanto, universal - quase não causa mais espanto nem permite acusações razoavelmente sustentáveis de relativismo, o que se deve ao clima contemporâneo de rejeição generalizada ao fundacionismo. Todavia, o segundo momento é a utilização da concepção de justiça política, obtida filosoficamente, como instrumento para que "todos os cidadãos" possam examinar suas "instituições políticas e sociais". Isto remete à questão que deixamos pendente anteriormente, sobre qual a proximidade filosófica adequada para examinar as "realidades morais e políticas", e gera outra questão, isto é, se a expressão "todos os cidadãos" deveria incluir os filósofos, enquanto tais, ou se a tarefa da Filosofia política se encerraria no primeiro momento, aquele da organização ou articulação de ideias e princípios. As respostas a estas duas questões esgotarão aquilo que se pretende tratar neste artigo.

Sobre a proximidade, ou melhor, sobre a distância conveniente que a Filosofia deveria manter do turbilhão político cotidiano, não há muita dúvida no que se refere à posição da Filosofia tradicional, como Walzer 
recorda em uma afirmativa paradigmática: "The philosopher, 'Wittgenstein wrote', is not a citizen of any community of ideas. That is what makes him into a philosopher." (Apud WALZER, 1981, p. 379) Esta posição de distanciamento, no caso da Filosofia política tradicional, é a consequência necessária da pretensão de obter teorias maximamente abstratas, por exemplo, sobre a justiça, a fim de dizer o que ela realmente é, determinar como aplicá-la em todas as comunidades e, consequentemente, dirigi-las: Global justice would seem to require a global theory - a single philosophically grounded account of what justice is that explains why it ought to be realized in exactly this way, everywhere. (WALZER, 2011, p. 42)

Para Walzer, assim como para Rawls, ${ }^{15}$ esta concepção do filósofo distanciado de toda comunidade não se sustenta mais no caso da Filosofia política contemporânea, ao menos se esta pretende ser útil, por exemplo, para a construção de concepções de justiça nas sociedades democráticas inevitavelmente pluralistas, daí a adoção, por ambos, da superficialidade filosófica, evitando doutrinas filosóficas abrangentes universalistas, bem como seu interesse pelas crenças e práticas compartilhadas por aquelas sociedades.

Quanto à questão do envolvimento do filósofo no exame e discussão das realidades morais e políticas de sua comunidade, não como cidadão comum, mas enquanto tal, Walzer parece explicitar aquilo que Rawls deixou implícito. Para o primeiro, o filósofo está sim incluído no conjunto dos cidadãos que, utilizando como instrumento uma concepção política de justiça filosoficamente elaborada ou articulada, por exemplo, podem examinar, de perto, mas ainda filosoficamente, "se suas instituições políticas e sociais são justas ou não". Certamente, este papel não foi tradicionalmente cumprido pelos filósofos e as tentativas de defendê-lo, como feitas por Walzer, causam estranhamento e acusações de relativismo como aquela já mencionada de Dworkin, que nega até mesmo sua possibilidade. ${ }^{16}$ Esta oposição entre o modo como Dworkin e Walzer compreendem o papel da Filosofia, sendo ambos herdeiros legítimos e assumidos da tradição rawlsiana, faz lembrar a disputa entre a direita e a esquerda hegeliana. A proveniência comum daqueles dois pode ser muito útil, como já foi para compreender e situar as posições dos hegelianos no espectro filosófico da

\footnotetext{
15 'I don't hope to make arguments that are conclusive for all human beings in all societies that exist or will exist or have ever existed. [...]Not that such an idea makes it impossibly hard to arrive at principles of justice; it makes it too easy, for the principles need not apply to anyone in particular. The hard task is to find principles latent in the lives of the people Dworkin and I live with, principles that they can recognize and adopt." (WALZER, 1983, ?) "A filosofia como a busca da verdade a respeito de uma ordem metafísica e moral independente não pode, creio, oferecer uma base compartilhada operativa para uma concepção política da justiça numa sociedade democrática.” (RAWLS, 1992, p. 34)

16 "So a theory that ties justice to conventions would not be acceptable even if it were available to us." (DWORKIN, 1983, p. 10)
} 
época, para ilustrar a especificidade do tipo de Filosofia política engajada defendida por Walzer. O pertencimento de ambos à mesma tradição teórica e a sua especificidade de polos opostos dela podem ser utilmente ilustrado pela metáfora do espelho. Como já mostrado, o "ponto de vista publicamente reconhecido" (Cf. RAWLS, 1992, p. 32), que Rawls pensa que pode ser utilizado pelos cidadãos como critério de justiça, não pretende ser uma visão sobre uma suposta ideia de justiça universal, externa à comunidade e incondicionalmente válida, mas sim um ponto de vista sobre aquilo que é compartilhado pelos cidadãos, uma visão de suas crenças compartilhadas refletidas no espelho filosófico rawlsiano. Dworkin, por sua vez, considera espelhos desse tipo inúteis para os propósitos da Filosofia política, uma vez que não seriam capazes de obter o que é justo em si mesmo, mas apenas o que parece justo para a comunidade cujo consenso reflete:

\begin{abstract}
But the principles of justice we use to decide which features of a community are relevant to a just distribution of its goods and opportunities - and therefore which principles we should struggle to promote politically-must be principles we accept because they seem right rather than because they have been captured in some conventional practice. Otherwise political theory will be only a mirror, uselessly reflecting a community's consensus and division back upon itself.
\end{abstract}

Contra esta posição universalista de Dworkin, que já foi insistentemente mostrada como insustentável diante do fato do pluralismo, a concepção do filósofo político engajado de Walzer se mostra como um profícuo e sustentável desenvolvimento interpretativo da posição de Rawls, pois é totalmente coerente com esta última pensar o filósofo como crítico imanente de sua própria comunidade, como alguém que, sem apelar autoritariamente para quaisquer princípios externos, apenas reflete, mostrando para seus concidadãos o reflexo de suas crenças e ideais compartilhados, tão frequentemente distorcidos em práticas e instituições injustas e, portanto, precisando de uma crítica filosófica conectada com aqueles: "A connected critic.[...]It is the critic who holds the mirror up to his compatriots and says: 'Here are your ideals, look in the mirror and see who you really are'.” (WILLIAMS, 2012, p. 384) 


\section{Referências bibliográficas:}

- BERNSTEIN, Richard J.. One Step Forward, Two Steps Backward Richard Rorty on Liberal Democracy and Philosophy. In: Political Theory, Volume 15, No. 4, November 1987, p. 538-563.

- DWORKIN, Ronald. To Each His Own. In: The New York Review of Books, Volume 30, Number 6, April 1983.

- HABERMAS, Jürgen. Consciência moral e agir comunicativo. Rio de Janeiro: Tempo Brasileiro, 2003.

- KYMLICKA, Will. Filosofia política contemporânea: uma introdução. São Paulo: Martins Fontes, 2006.

- MOUFFE, Chantal. Democracia, cidadania e a questão do pluralismo. In: Política \& Sociedade, No 3, outubro de 2003, p. 11-26.

- RAWLS, John. Justiça como equidade: uma concepção política, não metafísica. In: Lua Nova, no 25, 1992, p. 25-59.

- ___ O L Liberalismo político. São Paulo: Martins Fontes, 2011.

- _ Political Liberalism: Reply to Habermas. In: The Journal of Philosophy, Vol. 92, No. 3 (March, 1995), p. 132-180.

- RORTY, Richard.. Democracia e Filosofia. In: Revista Redescrições, Ano 4, Número 3, 2013.

- How Relevant is Philosophy to Politics?. Richard Rorty born digital files, 1988-2003. UCIspace @ the Libraries.

- SANDEL, Michael J. . O liberalismo e os limites da justiça. Lisboa: Fundação Calouste Gulbenkian, 2005.

- VATTIMO, Gianni. VATTIMO, Gianni. (Org.) El pensamento débil. Madrid: Ediciones Cátedra, 1988.

- WALZER, Michael. Achieving Global and Local Justice. In: Dissent, Volume 58, Number 3, Summer 2011, p. 42-48.

- ___ Esferas da justiça: uma defesa do pluralismo e da igualdade. São Paulo: Martins Fontes, 2003.

- __ . Interview with Michael Walzer. In: Thinking politically: essays in political theory. New Haven: Yale University Press, 2007.

Política e paixão: rumo a um liberalismo mais igualitário. São

Paulo: Martins Fontes, 2008.

$-$ Philosophy and Democracy. In: Political Theory, Vol. 9, No. 3 (Aug., 1981), pp. 379-399.

- _ . Pluralism and Social Democracy. In: Dissent Magazine, Winter, 1998.

The Communitarian Critique of Liberalism. In: Political Theory, Vol. 18, No. 1 (Feb., 1990), pp. 6-23. 
"Spheres of Justice": An Exchange. Michael Walzer, reply by Ronald Dworkin. In: The New York Review of Books, Volume 30, Number 12, July 21, 1983.

- WILLIAMS, Jeffrey J. . Criticism and Connection: An Interview with Michael Walzer. In: Symploke, Vol. 20, Nos. 1-2 (2012), p. 371-390. 